\title{
Book Symposium: Duncan Pritchard, Epistemic Angst (Princeton University Press, 2015, xiii +236 pages)
}

Article info

CDD: 121

Received: 20.03.2018; Accepted: 23.03.2018

DOI: http://dx.doi.org/10.1590/0100-6045.2018.V41N1.DP

Keywords:

Knowledge

Skepticism

Externalism

Wittgenstein

\section{ABSTRACT}

This book symposium features three critical pieces dealing with Duncan Pritchard's book, 'Epistemic Angst'; the symposium also contains Pritchard's replies to his critics.

\section{Duncan Pritchard 1,2}

${ }^{1}$ University of California, Irvine

Department of Philosophy

85 Humanities Instructional Building

University of California

Irvine, CA 92697-4555

USA

\&

2 University of Edinburgh

Department of Philosophy

Scotland

duncan.pritchard@ed.ac.uk

\section{Nicola Claudio Salvatore 4}

${ }^{4}$ University of Campinas

Department of Philosophy

Brazil, SP

nicolaclaudiosalvatore@googlemail.com

\author{
Michael Veber ${ }^{3}$ \\ ${ }^{3}$ East Carolina University \\ Department of Philosophy \\ EUA \\ VEBERM@ecu.edu
}

\section{Rodrigo Borges 5}

${ }^{5}$ Pontifícia Universidade Católica do Rio Grande do Sul

Brazil, SP

epistemen@gmail.com 


\section{Duncan Pritchard}

I have struggled with the problem of radical skepticism for many years. Epistemic Angst (Princeton University Press, 2015) opens by saying that this problem is both my first love, philosophically speaking, and my true love. It was certainly this puzzle that got me hooked into philosophy, and it was this puzzle that I found myself returning to at regular intervals. In earlier work- - especially Epistemic Luck (Oxford University Press, 2005)-I tried to meet the difficulty head-on, by offering a form of neo-Mooreanism that was motivated by epistemic externalism and situated within a research program I referred to as anti-luck epistemology. ${ }^{1}$ The careful reader of this book will have spotted, however, that I was not fully persuaded, in that the anti-skeptical proposal on offer starts to look very much like a "skeptical solution" once the details are unpacked. Indeed, I found myself arguing in effect that a form of radical skepticism that is aimed specifically at the rational standing of our beliefs was pretty much correct.

Over the years, my response to radical skepticism became increasingly bifurcated. On the one hand, I developed an anti-skeptical theory (the essentials of which were already present in Epistemic Luck) that was inspired by Wittgenstein's (1969) remarks on the structure of rational evaluation in On Certainty. ${ }^{2}$ Simultaneously, I also advanced a separate proposal, inspired by John McDowell's (e.g., 1995) work, which was cast along epistemological disjunctivist lines. On the face of it, these two proposals are radically different. Nonetheless, I was convinced that they belonged together, though at the outset I couldn't quite see how to connect them. Fortunately, since each of these

1 I submit that anti-luck epistemology is still going strong, even though I now realize that it doesn't contain the materials to deal with radical scepticism. That is, I now realize that the philosophical task of offering a theory of knowledge is orthogonal to the philosophical challenge of showing whether, contra the radical skeptic, we have any knowledge. In any case, I claim that anti-luck epistemology is adequate to the former task, as part of a wider view I call anti-luck virtue epistemology (or, more recently, anti-risk virtue epistemology). For more on anti-luck epistemology in general, see Pritchard (2005a; 2007; 2015a). For more on anti-luck virtue epistemology, see Pritchard, Millar \& Haddock (2010, chs. 1-4) and Pritchard (2012a). For more on anti-risk virtue epistemology, see Pritchard (2016; forthcoming).

2 Henceforth referred to as 'OC'.

Manuscrito - Rev. Int. Fil. Campinas, v. 41, n. 1, pp. 115-165, jan.-mar. 2018. 
theories is highly contentious in its own right, it was inevitable that I only ever presented work on one of the two positions at any given time, and so I could gloss over the issue of how these two parts of my overall anti-skeptical view related to one another. (Occasionally, however, someone who had heard a recent talk of mine on the other proposal would challenge me to explain myself.)

I'm not quite sure exactly when the epiphany occurred, but it was certainly while working on the book that would be published as Epistemological Disjunctivism (Oxford University Press, 2012) that I saw the light. Very roughly, epistemological disjunctivism is the view that when it comes to paradigm cases of perceptual knowledge, the rational support available to the subject is both reflectively accessible and factive. In particular, one's reflectively accessible rational basis for knowing that $p$ can be that one sees that $p$, where seeing that $p$ entails $p$. As far as epistemological orthodoxy goes, such a position is held to be straightforwardly incoherent.

The goal of Epistemological Disjunctivism was to explain why this position, far from being the utterly mad proposal that many in contemporary epistemology suppose it to be, is in fact perfectly defensible. This point is crucial because, as I also argued in this book, epistemological disjunctivism is a stance that is rooted in our ordinary epistemic practices, and would be highly desirable if true. Accordingly, if the philosophical reasons why we have rejected this natural position turn out to be dubious, such that it is a live theoretical option after all, then a powerful case can be made that we should embrace it.

Since epistemological disjunctivism is such a contentious position, one of the self- imposed constraints I operated under in that monograph was that I would defend the view by appealing only to further claims that ought to be acceptable to all epistemologists. This meant that when I got to the point in the book where I demonstrate the anti-skeptical potential of the view, it simply wasn't an option to bring in Wittgenstein's radical account of the structure of rational evaluation, as most epistemologists would regard such a view as highly contentious. Instead, epistemological disjunctivism was obliged to stand on its own two feet. The result was a new kind of neo-Mooreanism, this time set within a provocative form of non-classical epistemic internalism rather than epistemic externalism. But I was acutely aware that the anti- skeptical story I was telling was incomplete in a fundamental way, and that the full solution lay in integrating epistemological disjunctivism with the Wittgensteinian proposal.

Manuscrito - Rev. Int. Fil. Campinas, v. 41, n. 1, pp. 115-165, jan.-mar. 2018. 
In order to understand why, we need to revisit a debate that occurred in the literature just over a decade ago, and which I was fortunate to play a (relatively minor) part in. This concerned the logical structure of radical skeptical arguments, and in particular whether the formulation of radical skepticism that turns on a closure-style principle is logically distinct from a superficially very similar formulation of radical skepticism that turns on what is known as an underdetermination principle. My own contribution to this debate, such as it was — see Pritchard (2005a, pt. 1; 2005b) —was to defend the claim that these epistemic principles are logically distinct, and that this may have important implications for the debate regarding radical skepticism. It was only when I was writing Epistemological Disjunctivism, however, that I came to the view that the logical difference between these two epistemic principles is in fact profoundly important for our understanding of the two formulations of the skeptical argument.

In particular, I came to realize that this logical difference reveals that these two formulations of radical skepticism, while superficially similar, are in fact arising out of different sources. Underdetermination-based radical skepticism is trading on a specific point about what I call the insularity of reasons - roughly, how the rational support our worldly beliefs enjoy, even in the best case, is compatible with their widespread falsity. In contrast, closure-based radical skepticism trades on a very different claim, which is what I call the universality of rational evaluation - roughly, that there are no in principle limits on the extent to which our beliefs can be rationally evaluated, such that universal rational evaluations are entirely possible. Once one understands how these two formulations of the skeptical argument arise out of different sources, then it becomes apparent why the logical differences between the two epistemic principles on which they turn are so important. In particular, what one discovers is that these two formulations of the skeptical argument really constitute distinct skeptical problems that require distinct solutions.

By recognizing this point, I was able to get a handle on just what is right and what is unsatisfying about epistemological disjunctivism from the perspective of radical skepticism. This proposal confronts the insularity of reasons thesis head-on, and demonstrates that such a thesis, far from being common sense, is in fact the product of dubious philosophical theory. As such, epistemological disjunctivism is the antidote to underdetermination-based radical skepticism. But if one applies this idea, ungarnished with Wittgenstein's insight about the structure of rational evaluation, to closure-based radical skepticism, then one 
gets an extremely epistemically immodest (and hence unpalatable) proposal, one that contends that we can have a factive rational basis for dismissing radical skeptical hypotheses.

How does the Wittgensteinian account of the structure of rational evaluation help on this score? Well, the core thought in this account is that the very idea of a fully general rational evaluation-whether of a negative (i.e., radically skeptical) or a positive (i.e., traditional anti- skeptical, such as Moorean) nature-is simply incoherent. Instead, Wittgenstein argues that it is in the very nature of a system of rational evaluation that it takes certain basic commitments - the "hinge" commitments, as he called them — as immune to rational evaluation. Surprisingly, these hinge commitments can be regarding such apparently mundane propositions as that one has two hands. According to Wittgenstein, it is only with these hinge commitments in the background that rational evaluation is even possible. The upshot is that rational evaluation is an essentially local phenomenon. Moreover, this is not because of some incidental lack on our part (e.g., a lack of imagination or consistency), but rather reflects the very nature of what is involved in rational evaluation. (As Wittgenstein expressed the matter, his point was about the "logic" of rational evaluation.)

The challenge posed by the Wittgensteinian account of the structure of rational evaluation is to explain what purchase, exactly, it offers us on the skeptical problem. On my reading of Wittgenstein, the thought is that it gains us a very good grip on closure-based radical skepticism by offering us principled grounds for rejecting the universality of rational evaluation thesis. Crucially, however, my reading of Wittgenstein enables us to reject the universality of rational evaluation thesis without thereby rejecting the closure principle, thereby ensuring that the view can retain all of our commonsense epistemological commitments. As I argue, our hinge commitments, properly understood, are simply not the kind of propositional attitude to which the closure principle (again, properly understood) is applicable. It follows that the Wittgensteinian rejection of the universality of rational evaluation is entirely consistent with the closure principle, since the latter simply does not apply to our hinge commitments.

This point is very important to the undercutting credentials of this form of anti-skepticism. Wittgenstein was certainly very keen to offer a response to the radical skeptical problem that demonstrated that it was a puzzle that was arising out of dubious philosophical claims that are masquerading as common sense.

Manuscrito - Rev. Int. Fil. Campinas, v. 41, n. 1, pp. 115-165, jan.-mar. 2018. 
According to Wittgenstein, the radical skepticism problem is really a product of faulty philosophical theory, rather than representing a genuine paradoxical tension in our most fundamental epistemic commitments. The skeptical "paradox" is thus undercut, in that it is shown to not be a bona fide paradox at all (this is as opposed to the paradox being overridden, which is when a genuine paradox is resolved by offering a plausible form of philosophical revisionism). If the closure principle is a highly intuitive principle, then it is all to the good as far as an undercutting anti- skeptical proposal goes that it does not involve the denial of this principle.

We can now see how the Wittgensteinian proposal, when understood in the right way, can help epistemological disjunctivism with its response to radical skepticism. Whereas epistemological disjunctivism is focused on the underdetermination-based formulation of radical skepticism, which trades on the underlying insularity of reasons thesis, the Wittgensteinian proposal is instead aimed at the closure-based formulation of radical skepticism, which trades on the underlying universality of rational evaluation thesis. The crux of the matter is that if we can combine these proposals, then potentially we can offer a unified treatment of radical skepticism that deals with both formulations of the problem.

Can we combine these proposals? On the face of it, they look very different; indeed, they look antithetical, and competing (and are often taken to be so). Whereas the Wittgensteinian proposal emphasizes the locality of rational evaluation, and hence the locality of rational support, the McDowellian proposal emphasizes the strength of the rational support available to us in paradigm conditions, in that it is factive. But these differences are superficial. In fact, these proposals work very well with each other, in that they are not only compatible, but also mutually supporting and philosophically in the same spirit.

The compatibility claim is just the idea that the supposed tension between these views is merely superficial. There is nothing in the idea of rational evaluation being essentially local that precludes the possibility of factive rational support in the perceptual case. And there is nothing in the idea of factive rational support that excludes the possibility that all rational evaluation is local. Once one recognizes the compatibility of these two theses, then one can see how they might be combined, and how, in particular, they might be employed to support each other. The basic idea is that each proposal is more plausible when combined with its sister view. So, it is easier to live with the essential locality of rational evaluation if one is also able to demonstrate that paradigm

Manuscrito - Rev. Int. Fil. Campinas, v. 41, n. 1, pp. 115-165, jan.-mar. 2018. 
cases of perceptual rational support are factive. And it is easier to live with the idea that paradigm cases of perceptual rational support are factive if one embraces the essential locality of rational evaluation (i.e., because one is not thereby committed to the epistemic immodesty of supposing that one can have a factive rational basis for dismissing radical skeptical hypotheses). Note too the extent to which these proposals are in the same spirit. We have already seen that the Wittgensteinian proposal is an undercutting treatment of the skeptical "paradox." But note that this also applies to epistemological disjunctivism, in that the guiding idea behind this view is that we have been seduced, on faulty theoretical grounds, into regarding a dubious theoretical claim (regarding the insularity of reasons) as an item of mere common sense. Both of the formulations of the skeptical

problem in play, whether closure-based or underdetermination-based, are thus shown to be merely pseudo-problems.

I call the unified defense against radical skepticism the biscopic proposal. It is, admittedly, an ugly name-I have tried hard to find a better moniker but without success. But, despite its ugliness, it does convey the bare essentials of the proposal. This is that we have, completely unbeknownst to us, been looking at this problem through, as it were, only one eye-only one eye at a time anyway-and that we need to use both of our philosophical "eyes" in order to see the problem aright. Only then can we gain the right perspective on the problem and thereby recognize what the correct solution to the problem must be.

A final comment is in order about the very notion of epistemic angst. The problem of radical skepticism has always been a very real existential issue for me, and so I do not use this terminology lightly. Discovering that the skeptical problem has no clear answer is something that should unsettle any responsible inquirer. Note, though, that while I believe the solution I offer to the skeptical problem genuinely is a remedy for epistemic angst, this is not to say that the anxiety in question will be entirely removed. This is because I think there is an inevitable psychological vestige of skeptical doubt that remains even once the solution has been embraced (albeit not one that is now tracking a genuine epistemic angst about one's epistemic situation).

I call this psychological state epistemic vertigo (or epistemic acrophobia, if one wants to be pedantic), in order to capture the idea that it is essentially a kind of phobic reaction to one's epistemic predicament. Just as one can suffer from 
vertigo when high up, even while fully recognizing that one is not in any danger, so I think that even after the problem of radical skepticism has been resolved, and hence the epistemic risk posed by this problem is defused, it can nonetheless be the case that one feels a residual unease about one's epistemic situation. The reason for this disquiet is embedded in the Wittgensteinian account of the structure of rational evaluation itself. For what Wittgenstein alerts us to is how one's apparently very ordinary commitments - such as that one has two hands - can be playing a quite striking role in the system of rational evaluation. Wittgenstein wrote that our hinge commitments "lie apart from the route travelled by inquiry" (OC, \$88). He means that the question of their rational standing simply never arises in normal conditions, and so we are unaware that these ordinary commitments play an extraordinary epistemic role. Once one has inquired into their rational standing, however-and the stimulus for this inquiry will almost certainly be philosophical in nature- then it is hard not to continue to be struck thereafter by their peculiarity.

Another way of putting this point is that while in everyday life we do not take it as given that universal rational evaluations are possible-indeed, we don't consider the issue at all-neither do we recognize that they are impossible. That's not to say that we don't recognize that our everyday practices of giving reasons for and against particular claims is local, as we surely do recognize this. The crux of the matter is rather that our practices of rational evaluation, while local, also seem to be entirely open to indefinite broadenings of scope. That is, there seems no inherent limits to the scope of rational evaluation, even if in practice it is always local in nature. That there is such an inherent limit - that a fully general rational evaluation, one that encompassed even our hinge commitments, is impossible-is a philosophical discovery. Moreover, in discovering it, we also realize that our everyday epistemic practices disguise this fact. It is thus unsurprising, then, that even once epistemic angst has been removed, epistemic vertigo might well remain, for we now have a perspective on our practices of rational evaluation that is in a certain sense completely unnatural. We have, as it were, epistemically "ascended" and adopted a vantage point that we would not normally adopt. From this unnatural vantage point, epistemic vertigo is a natural response.

My point is that one can accept that there is a genuine phenomenon of epistemic vertigo without thereby conceding anything of substance to the radical skeptic. Epistemic angst is averted-this is no skeptical solution of 
radical skepticism. But as with any engagement with a deep philosophical problem, things are not left entirely as they were before. ${ }^{3}$

Nicola Claudio Salvatore - Two Worries on Pritchard's Epistemic Angst

\section{The Cartesian skeptical paradox.}

The feature of Cartesian style arguments is that we cannot know certain empirical propositions (such as 'Human beings have bodies', or 'There are material objects') as we may be dreaming, hallucinating, deceived by a demon or be "brains in the vat" (BIV), that is, disembodied brains floating in a vat, connected to supercomputers that stimulate us in just the same way that normal brains are stimulated when they perceive things in a normal way. ${ }^{4}$ Therefore, as we are unable to refute these skeptical hypotheses, we are also unable to know propositions that we would otherwise accept as being true if we could rule out these scenarios.

Cartesian arguments are extremely powerful as they rest on the Closure principle for knowledge. According to this principle, knowledge is "closed" under known entailment. Roughly speaking, this principle states that if an agent knows a proposition (e.g., that she has two hands), and competently deduces from this proposition a second proposition (e.g., that having hands entails that she is not a BIV), then she also knows the second proposition (that she is not a BIV). More formally:

\section{The "Closure" Principle}

If $\mathrm{S}$ knows that $p$, and $\mathrm{S}$ competently deduces from $p$ that $q$, thereby coming to believe that $q$ on this basis, while retaining her knowledge that $p$, then $\mathrm{S}$ knows that $q^{5}$.

3 This précis is an abbreviated version of the introduction to Epistemic Angst.

4 See Putnam (1981).

5 This is essentially the formulation of the Closure principle defended by Williamson $(2000,117)$ and Hawthorne $(2005,29)$.

Manuscrito - Rev. Int. Fil. Campinas, v. 41, n. 1, pp. 115-165, jan.-mar. 2018. 
Let's take a skeptical hypothesis, $\mathrm{SH}$, such as the BIV hypothesis mentioned above, and M, an empirical proposition such as "Human beings have bodies" that would entail the falsity of a skeptical hypothesis. We can then state the structure of Cartesian skeptical arguments as follows:

(S1) I do not know not-SH

(S2) If I do not know not-SH, then I do not know M

(SC) I do not know M

Considering that we can repeat this argument for each and every one of our empirical knowledge claims, the radical skeptical consequence we can draw from this and similar arguments is that our knowledge is impossible.

\section{Wittgenstein on scepticism; a minimal reading.}

A way of dealing with 'Cartesian style' skepticism is to deny the premise S1) of the skeptical argument, thus affirming contra the skeptic that we can know the falsity of the relevant skeptical hypothesis.

For instance, in his " $A$ defence of commonsense" (1925, henceforth DCS) and "Proof of the external world" (1939, henceforth PEW), G. E. Moore famously argued that we can have knowledge of the 'commonsense view of the world', that is of statement such as 'Human beings have bodies', 'There are material objects' or 'The earth existed long before my birth' and that this knowledge would offer a direct response against skeptical worries.

Wittgenstein wrote the 676 remarks published posthumously as On Certainty (1969, henceforth OC) under the influence of DCS and PEW, and in particular in the context of conversations he had about these papers with his friend and pupil Norman Malcolm ${ }^{6}$.

As I have briefly mentioned supra, according to Moore, it is possible to provide a direct refutation of Cartesian-style skepticism, thus claiming contra the skeptic that we can know the denials of skeptical hypotheses.

\footnotetext{
${ }^{6}$ While writing OC Wittgenstein was also heavily influenced by Henry Newman's lectures on religious beliefs (see Newman 1844, 1870-1985). For a more detailed analysis of the relationship between Newman's and Wittgenstein's anti-skeptical strategies, see Pritchard (2000).
}

Manuscrito-Rev. Int. Fil. Campinas, v. 41, n. 1, pp. 115-165, jan.-mar. 2018. 
But, Wittgenstein argues, to say that we simply 'know' Moore's 'obvious truisms' is somewhat misleading, for a number of reasons.

Firstly (OC 349, 483), because in order to say 'I know' one should be able, at least in principle, to produce evidence or to offer compelling grounds for his beliefs; but Moore cannot ground his knowledge-claims with evidence or reasons because (OC 245) his grounds aren't stronger than what they are supposed to justify. As Wittgenstein points out, if a piece of evidence has to count as compelling grounds for our belief in a certain proposition then that evidence must be at least as certain the belief itself. This cannot happen in the case of a Moorean 'commonsense certainty' such as 'I have two hands' because, at least in normal circumstances, nothing is more certain than the fact that we have hands (Pritchard, 2014). As Wittgenstein writes in OC:

If a blind man were to ask me "Have you got two hands?" I should not make sure by looking. If I were to have any doubt of it, then I don't know why I should trust my eyes. For why shouldn't I test my eyes by looking to find out whether I see my two hands? What should be tested by what? (OC 125).

Imagine, for instance, that one attempted to legitimate one's claim to know that $\mathrm{p}$ by using the evidence that one has for $\mathrm{p}$ (for example, what one sees, what one has been told about $\mathrm{p}$ and so on). Now, if the evidence we adduced to support $\mathrm{p}$ was less secure than $\mathrm{p}$ itself, then this same evidence would be unable to support $\mathrm{p}$ :

My having two hands is, in normal circumstances, as certain as anything that I

could produce in evidence for it. That is why I am not in a position to take the sight of my hand as evidence for it (OC 250).

Moreover, Wittgenstein argues, a knowledge-claim can be challenged by, for instance, the appeal to evidence and reasons; more generally, when we challenge a knowledge claim we can recognize what and if something has gone wrong in the agent's process of knowledge-acquisition. Things are somewhat different in the case of the denials of Moore's 'obvious truisms of the

Manuscrito - Rev. Int. Fil. Campinas, v. 41, n. 1, pp. 115-165, jan.-mar. 2018. 
commonsense'; if, for instance, I believe that I am sitting in my room whilst I am not, there are no grounds on which this belief could be explained as a mistake, as an error based on negligence, fatigue or ignorance. On the contrary, a similar 'false belief' would more likely be the result of a sensorial or mental disturbance (OC 526). As Moyal-Sharrock points out (2004, 74), in fact, for Wittgenstein if someone was holding seriously a denial of Moore's 'truisms' (i.e., she believed she had no body or that both her parents were men) we would not investigate the truth-value of her affirmations, but instead her ability to understand the language she is using or her sanity (OC 155).

If Moore's 'commonsense certainties' are not knowable, they are nonetheless immune from rational doubt. This is so, argues Wittgenstein (OC 310) because doubts must be based on grounds; that is, they have to be internal to a particular practice and must be in some way or another justified. If they aren't, they are constitutively empty. To illustrate this point, Wittgenstein gives the example (OC 310) of a pupil who constantly interrupts a lesson, questioning the existence of material objects or the meaning of words; far from being a legitimate intellectual task, the pupil's doubt will lack any sense and will at most lead to a sort of epistemic paralysis, for she will just be unable to learn the skill or the subject we are trying to teach her (OC 315).

Accordingly, as per Wittgenstein, all reasonable doubts presuppose certainty (OC 114-115); that is, the very fact that we usually raise doubts of every sort at the same time shows and implies that we take something for granted. For example, a doubt about the real existence of an historical figure presupposes that we consider certain an 'obvious truism of the commonsense' such as, 'The world existed a long time before my birth'; a doubt about the existence of a planet presupposes the absence of any doubt about the existence of the external world and so on (OC 114-115, 514-515).

Not knowable or doubtable, as per Wittgenstein Moore's 'commonsense certainties' are 'hinges'; a term he uses on different occasions, as in OC 341-3, where he writes:

\footnotetext{
"The question that we raise and our doubts depend on the fact that some propositions are exempt from doubt, are as it were the hinges on which those turn [...] that is to say, it belongs to the logic of our scientific investigations that certain things are in deed not doubted [...] If I want the door to turn, the hinges must stay put".
}

Manuscrito - Rev. Int. Fil. Campinas, v. 41, n. 1, pp. 115-165, jan.-mar. 2018. 
That is to say, 'hinges' are just apparently empirical contingent claims; on closer inspection, they perform a different, more basic role in our epistemic practices.

\section{Pritchard's anti-skeptical strategy}

With this points in mind, we can now turn our attention to Pritchard's antiskeptical strategy in Epistemic Angst .(2015).

To understand his proposal, recall the following remark we have already quoted supra:

If you are not certain of any fact, you cannot be certain of the meaning of your words either [...] If you tried to doubt everything you would not get as far as doubting anything. The game of doubting itself presupposes certainty (OC 114-115).

As per Pritchard, here Wittgenstein would claim that the same logic of our ways of inquiry presupposes that some propositions are excluded from doubt; and this is not irrational or based on a sort of blind faith, but rather belongs to the way rational inquiries are put forward (see OC 342)7. As a door needs hinges in order to turn, any rational evaluation would require prior commitment to an unquestionable proposition/set of 'hinges' in order to be possible at all.

A consequence of this thought $(2015,102)$ is that any form of universal doubt such as the Cartesian skeptical one is constitutively impossible 8 ; there is simply no way to pursue an inquiry in which nothing is taken for granted. In other words, the same generality of the Cartesian skeptical challenge is based on a misleading way of representing the essentially local nature of our enquiries.

A proponent of Cartesian skepticism looks for a universal, general evaluation of our beliefs; but crucially there is no such thing as a general evaluation of our beliefs, whether positive (anti-skeptical) or negative

7 Cfr OC 342: [...] it belongs to the logic of our scientific investigations that certain things are indeed not doubted.

${ }^{8}$ See OC 450: "A doubt that doubted everything would not be a doubt".

Manuscrito - Rev. Int. Fil. Campinas, v. 41, n. 1, pp. 115-165, jan.-mar. 2018. 
(skeptical), for all rational evaluation can take place only in the context of 'hinges' which are themselves immune to rational evaluation.

An important consequence of Pritchard's proposal is that it will not affect Closure. Each and every one of our epistemic practices rests on 'hinges' that we accept with a certainty that is the expression of what Pritchard calls "hinge' commitment': an a-rational commitment toward our most basic belief that, as we mentioned above, is not itself opened to rational evaluation and that importantly is not a belief.

As we have seen, this commitment would express a fundamental a-rational relationship toward our most basic certainties, a commitment without which no knowledge is possible. Crucially, our basic certainties are not subject to rational evaluation: for instance, they cannot be confirmed or dis-confirmed by evidence and thus they are non-propositional in character (that is to say, they cannot be either true or false). Accordingly, they are not beliefs at all. This can help us retain both the Closure principle and our confidence in our most basic certainties. Recall the reformulation of the Closure principle we have already encountered supra:

\section{The Competent Deduction Principle}

If $\mathrm{S}$ knows that $p$, and $\mathrm{S}$ competently deduces from $p$ that $q$, thereby coming to believe that $\quad q$ on this basis, while retaining her knowledge that $p$, then $\mathrm{S}$ knows that $q$.

The crucial aspect of this principle to note $(2015,90-102)$ is that it involves an agent forming a belief on the basis of the relevant competent deduction; the idea behind Closure is in fact that an agent can come to acquire new knowledge via competent deduction, where this means that the belief in question is based on that deduction. Accordingly, if we could not rule out a skeptical scenario such as the BIV one, we would be unable to know Moore's 'obvious truisms of the commonsense' such as, 'Human beings have bodies' or 'There are external objects' and thus, given Closure, we would be unable to know anything at all.

But our most basic certainties are not beliefs; rather, they are the expression of a-rational, non-propositional commitments. Thus, the skeptic is somewhat right in saying that we do not know Moore's 'obvious truisms of the common sense 'and that, also, we cannot know whether we are victim of a SH or not; but this will not lead to skeptical conclusions, for our 'hinge commitments' are not 
beliefs so they cannot be objects of knowledge. Therefore, the skeptical challenge is misguided in the first place 9 .

\title{
4. Epistemic vertigo and epistemic relativism.
}

However, even if we agree with Pritchard that a general evaluation of our beliefs is somewhat impossible and self-refuting there is still another deep concern that the 'hinge commitment strategy' has to face. Recall that following this proposal, all our epistemic practices are essentially local in nature and rest on unsupported 'hinge commitments'.

If this approach can help us to block the skeptical challenge it will nonetheless have a cost, that Pritchard calls epistemic vertigo:

\begin{abstract}
"In short, it is one thing to quite properly employ an essentially local system of rational evaluation without ever recognizing that it is essentially local, and another thing entirely to come to realize that one's system of rational evaluation is local in this fashion (even if one is at the same time convinced that systems of rational evaluation are by their nature local). Elsewhere, I have referred to this intellectual anxiety induced by radical skepticism, even when in possession of an undercutting solution to the problem, as epistemic vertigo.
\end{abstract}

Roughly, the idea is that a by-product of the very process of engaging with radical ' skepticism, even when successfully engaging with this problem, is that it involves a kind of

\footnotetext{
${ }^{9}$ It should be noted that Pritchard's reflections on 'hinges' are only a part of a more complex anti-skeptical framework.; the other part is called epistemological disjunctivism , that while primarily meant to address the únderdetermination-based'skeptical challenge and not the Closure-based one, does nonetheless support his treatment of Cartesian skepticism. To present and discuss the merits of Pritchard's epistemological disjunctivism would go beyond the scope of this essay and is thus not a task I shall set myself here.
} 
reflection-a kind of epistemic ascent, if you will—that can induce intellectual anxiety $[\ldots\}$ Our engagement with the problem, and the associated epistemic ascent, leads us to seek an overall perspective on our epistemic position, and this generates intellectual

anxiety. But even once we are assured that there is nothing to fear and that our epistemic position is as secure as one might reasonably expect (and certainly not subject to the specific threats outlined by the radical skeptic anyway), the anxiety might well remain" (2015, 185, 186, my italics).

That is to say, when skeptical arguments are not in play, we do not realize the fact that our epistemic practices are made within the boundaries of a number of a-rational 'hinge commitments' and that a general evaluation of our beliefs is impossible; still, when dealing with Radical skeptical scenarios, we do realize that our epistemic practices are all local in nature. If from a side this will block the skeptical challenge, by showing us that the kind of universal evaluation of our beliefs proposed by the skeptic is constitutively self-refuting, it would nonetheless have a cost; namely, it will lead us to the recognition of the fact that any kind of epistemic evaluation is local and, more importantly, rest on ungrounded 'hinge commitments' not open to epistemic evaluation. This might lead, and indeed does lead, not only to a sort of intellectual discomfort, but more seriously to a sort of anxiety with regard to our epistemic status. As Pritchard writes at some point:

"Given that such natural intellectual inclinations underlie the ascent to skepticism-friendly reasoning, it should be no wonder that our recognition that the kind of rational support at issue in a universal rational evaluation is unavailable can have such a giddying effect, even once we explicitly disengage the detached epistemic perspective from the attempt to undertake universal rational evaluations. Natural aspirations are hard to shake, and one cannot in any straightforward way unlearn what one has discovered about one's epistemic position. If reason cannot alter our hinge commitments, then it is unsurprising that it is also unable to completely eradicate our naturally arising anxieties, whether they be phobias like acrophobia or intellectual anxieties like epistemic vertigo. So even though there is a cure available for epistemic angst, there is also a sense in which angst 
of a certain kind - that is, epistemic vertigo-may remain even once the cure has been swallowed "' (2015, 187-188)

In other words, Pritchard recognizes the fact that while reason cannot undermine our confidence in our basic, a-rational hinge commitments, at the same time reason cannot completely undermine the 'epistemic discomfort'caused by the recognition of the fact that a general evaluation of our beliefs is constitutively impossible and, more importantly, that all our epistemic practices rest on unsupported 'hinge commitments'that are not in the market for epistemic evaluation of any sort.

According to Pritchard, this epistemic vertigo is not completely irrational; to the contrary, is rooted in a number of very legitimate and understandable concerns about our epistemic status. However, its significance is more psychological than philosophical, let alone epistemic; at the end of the day, what matters is that, by recognizing the local nature of our epistemic practices, we are able to rule out skeptical worries and at the same time to keep our confidence in our everyday knowledge claims.

At this stage, comes my first worry against this anti-skeptical strategy; is it really the case that epistemic vertigo has little to no epistemic significance, and is thus just the result of an understandable but misguided, attempt to attain a general evaluation of our beliefs?

Under skeptical scrutiny, we are forced to admit that all our epistemic practices rest on ungrounded presuppositions which are not open to epistemic evaluation of any sort. When skeptical hypotheses are in play, we are then forced to admit that all our knowledge rests on nothing but a-rational presuppositions such as habit, instinct and social or cultural commitments. Accordingly, Pritchard's 'hinge-commitment' anti-skeptical strategy might lead to a more subtle form of Humean skepticism which undermines our confidence in the very rationality of our ways of inquiry.

This point leads to another objection that might be raised against Pritchard's strategy. Consider the following entries of OC :

I could imagine Moore being captured by a wild tribe, and their expressing the suspicion that he has come from somewhere between the earth and the moon. Moore tells them that he knows etc. but he can't give them the grounds for his certainty, because they have fantastic ideas of human ability to fly and know nothing about physics...(OC 264).

Manuscrito - Rev. Int. Fil. Campinas, v. 41, n. 1, pp. 115-165, jan.-mar. 2018. 
Is it wrong for me to be guided in my actions by the propositions of physics? Am I to say I have no good ground for doing so? Isn't precisely this what we call a 'good ground'? Supposing we met people who did not regard that as a telling reason. Now, how do we imagine this? Instead of the physicist, they consult an oracle. (And for that we consider them primitive.) Is it wrong for them to consult an oracle and be guided by it? - If we call this "wrong" aren't we using our language-game as a base from which to combat theirs? And are we right or wrong to combat it? Of course there are all sorts of slogans which will be used to support our proceedings. Where two principles really do meet which cannot be reconciled with on another, then each man declares the other a fool and heretic (OC 608-611).

In the 'Moore and the Wild tribe' example mentioned above, the agents do not disagree over a particular thesis but rather on the very concept of 'evidence' and of what is epistemically relevant to the dispute. Moore believes in modern physics and more generally in the, so to say, scientific view of the world; the tribe does not consider physics as a telling reason and consults oracles instead. In Pritchard's jargon, Moore and the tribe belong to different epistemic communities in which different 'local hinge commitments' are in play.

As per Pritchard $(2010)^{10}$ his account of hinge commitment' would also represent a viable solution to the dispute between 'Moore and the Wild Tribe' and more generally between communities committed to different worldviews; this is because, he argues, given the local nature of our enquiries, all our epistemic disputes occur within a shared backdrop of basic 'hinge commitments ' (such as 'Human beings have bodies' and 'There are external objects'), and also because our commitments toward our most basic 'hinges' can nonetheless change, for instance when new information arise.

Still, even if both Moore and the Tribe share ' hinge commitments' such as 'There are external objects' and 'Human beings have bodies' (which would at least prevent disagreements on these 'basic certainties') they are nonetheless

10 Pritchard does not explicitly discuss this issue in (2015) but applies a similar Wittgenstein inspired'proposal to the problem of epistemic relativism in his (2010);hence, I am not sure whether the latter work still represent his views . However, for reason that will be clear below, I am convinced that the anti-skeptical account proposed in (2015) might still lead to unpalatable relativist conclusions.

Manuscrito - Rev. Int. Fil. Campinas, v. 41, n. 1, pp. 115-165, jan.-mar. 2018. 
committed to different 'local' commitments; Moore considers physics as a telling reason while the tribe does not.

But crucially, as our ' hinge commitments' are nothing but a-rational certainties not opened to epistemic evaluation of any sort, we would have no rational basis to solve the epistemic disagreement between Moore and the tribe and more generally between communities with different 'Local hinge commitments'. Thus, the 'hinge commitment' strategy would lead to the epistemic incommensurability thesis, that can be states as follows: Epistemic Incommensurability thesis

Is it possible for two agents to have opposing beliefs which are rationally justified to an equal extent where there is no rational basis by which either agent could properly persuade the other to revise their view (Pritchard, 2010, 5)

That is to say, if our epistemic practices are all based on a-rational commitments, than every epistemic community could legitimately hold its own practices, as they all rest on commitments that are both unquestionable and arational, thus outside any form of epistemic evaluation; accordingly, this proposal would license a form of epistemic relativism for which it would be impossible to solve disagreement between epistemic agents with radically different worldviews; a conclusion that is not more reassuring than skepticism itself.

\section{Concluding remarks.}

In this paper, I have argued that Pritchard's anti-skeptical strategy, and especially his account of ' hinge-commitments' , might lead to two unpalatable consequences. This is sop because this proposal can undermine both our confidence in the rationality of our epistemic practices and license an untenable form of epistemic relativism ${ }^{11}$.

11 For a general evaluation of a number of contemporary "Wittgenstein-inspired" anti-skeptical proposals, see also Salvatore $(2015,2017)$.

Manuscrito - Rev. Int. Fil. Campinas, v. 41, n. 1, pp. 115-165, jan.-mar. 2018. 


\section{Michael Veber - Can Hinge Epistemology Close the Door on Skepticism?}

In Epistemic Angst, Duncan Pritchard offers a "biscopic" approach to the problem of skepticism. Against closure-based skeptical arguments, he defends an epistemic theory grounded in remarks from Wittgenstein's On Certainty. Against underdetermination-based skeptical arguments, Pritchard offers his version of epistemological disjunctivism. The combination of these two approaches, Pritchard tells us, overcomes skeptical epistemic angst "without thereby conceding anything of substance to the radical skeptic." 12 I disagree.

\section{Hinge Epistemology is a Version of Skepticism.}

G.E. Moore felt certain of a bunch of things. Most famously: here is one hand (and here is another). ${ }^{13}$ But also: that he is wearing clothes and not naked, that he is speaking in a fairly loud voice and not singing, that there are other people in the room, that there are windows in that wall and a door in this one, ${ }^{14}$ that he has never been very far from the surface of the earth, that he was born at a certain time in the past, that his body was much smaller back then, and that the earth existed for many years before that. ${ }^{15}$ This list goes on but I'll stop there.

According to Wittgenstein, Moorean certainties are not ordinary objects of knowledge. Instead they function as "hinges". They are not subject to rational evaluation. Rather, they function as background constants that make all rational evaluation possible in the first place. The door moves but the hinge stays put.

As Pritchard sees it, our hinge commitments express propositions and thus have truth values but they are not objects of belief. Since they are not beliefs, they are not knowledge either. A hinge commitment might resemble knowledge or belief in certain ways but, being immune to rational evaluation, it does not qualify.

\footnotetext{
12 Pritchard, (2015, p.7).

13 Moore (1939).

14 Moore (1993).

15 Moore (1925).
} 
Most of the Moorean certainties listed above would be examples of what Pritchard calls "personal hinge commitments". These are ways of codifying the "über-hinge commitment" that we are not massively mistaken in our beliefs. Assuming normal circumstances, how could I be wrong about any of the things on Moore's list unless I am somehow massively deceived on more or less everything else? As Wittgenstein puts it in one place, to question a Moorean certainty is to impugn the very nature of evidence. ${ }^{16}$ In between the personal and the über-hinge is a third type, the "anti-skeptical hinge commitment". These are the negations of various skeptical hypotheses: that I am not a brain in a vat, that the world was not created by God five minutes ago, etc. ${ }^{17}$

The closure-based skeptical problem arises because it seems we have no way of knowing that far out skeptical hypotheses are untrue. Yet we seem to know a great many propositions that we also know are logically incompatible with those skeptical hypotheses. So if I know the one, how come I cannot know the other? Why can't I simply deduce that the earth was not created by God this morning from my knowledge that Napoleon won the battle of Austerlitz in 1805?

Plausible closure principles on knowledge allow that one can come to know what he competently deduces from something else he knows. But remember, the denials of skeptical hypotheses are hinge propositions and hinge propositions are never objects of belief. So one cannot arrive at belief in the denial of a skeptical hypothesis by deducing it (competently or otherwise) from an item of everyday knowledge. Whereof one cannot believe, thereof one cannot deduce. It isn't that closure fails, it's that it is simply inapplicable. And thus one kind of skeptical problem is solved.

Or is it? It is very odd, to this epistemologist anyway, to think any view that entails Moorean certainties are not objects of belief-and therefore not objects of knowledge-would constitute a solution to the skeptical problem.

\footnotetext{
${ }^{16}$ Wittgenstein (1969, \188).

${ }^{17}$ Prtichard (2015, p.94-98).
} 
Consider the following argument.

1. This is a hand is a hinge commitment.

2. Hinge commitments are not knowable.

3. Therefore, I do not know this is a hand.

The same argument would apply to any of Moore's certainties-e.g., I am wearing clothes, there are windows in that wall and a door in this one, I am not currently singing — as well as any others he forgot to list. It is a consequence of Pritchard's view that I do not know any of these things. There will be presumably non-hinge propositions that are knowable on Pritchard's view (though I don't find too many examples of them in the book). So the type of skepticism we end up with here is not as radical as some more familiar varieties. But it is a very radical version of skepticism nonetheless. Prittgensteinian epistemology offers not a refutation of skepticism but a new argument in favor of it. When a door closes (and a hinge stays put) a window opens.

\section{An Odd Pairing}

The skeptical nature of hinge epistemology also makes for an odd pairing with epistemological disjunctivism, at least to my palate. Epistemological disjunctivism has it that "in paradigm cases of perceptual knowledge the knowledge enjoys a support that is both factive and reflectively accessible." (124) But most of what I thought were paradigm cases of perceptual knowledge- here is a hand, for example — turn out not to be knowledge at all once I adopt the Prittgensteinian framework. So I don't know how to tell whether epistemological disjunctivism accounts for paradigm cases of perceptual knowledge because, if I adopt that framework, I no longer know what a paradigm case of perceptual knowledge is.

\section{Abominable Conjunctions}

Unlike that of Dretske and Nozick, Pritchard's view does not involve denying the most plausible closure principles on knowledge. But even so, his view still inherits what some see as the most absurd consequence of closure denial, namely, its commitment to "abominable conjunctions". 
Consider again the hypothesis that God created the universe just this morning. The negation of this is an anti-skeptical hinge commitment and thus unknowable. Therefore the following consequence results:

I know that Napoleon won the battle of Austerlitz a couple hundred years ago but, for all I know, the universe came into existence right before I made my coffee today.

In a footnote, Pritchard says that these kinds of abominable conjunctions "merely highlight the point that the scope of one's rational evaluation does not extend to one's hinge commitments" and once we become "appraised of the Wittgensteinian account of the structure of rational evaluation" they are no longer puzzling.18 But I am still puzzled.

To see why, consider the following argument:

1. Napoleon won the battle of Austerlitz a couple hundred years ago.

2. If Napoleon won the battle of Austerlitz a couple hundred years ago, then the universe did not come into existence right before I made my coffee today.

3. Therefore, the universe did not come into existence right before I made my coffee today.

Since hinge commitments express propositions, there is no obstacle to my knowing the logical form of this argument. Thus I know that it is valid. The first premise is an ordinary item of historical knowledge. The second premise contains a hinge commitment as the consequent of a conditional. But the conditional itself is an obvious necessary truth. There is no possible way the antecedent can be true and the consequent false. And I recognize that this is so even if the consequent is not subject to rational evaluation on its own. In other words:

I know the above argument is valid and that its premises are true but I don't know whether its conclusion is true.

18 Pritchard (2015, p.214).

Manuscrito-Rev. Int. Fil. Campinas, v. 41, n. 1, pp. 115-165, jan.-mar. 2018. 
Do I know that the above argument is sound? On the one hand, I know that any valid argument with true premises is sound. And I know that the above argument is valid and has true premises. But then we have:

I know that the above argument is sound but I don't know whether it has a true conclusion.

And yet I also know it is impossible for a sound argument to fail to have a true conclusion.

One might deny that I know the argument above is sound. But that won't help things much. Because then:

I know that the above argument is valid and that it has true premises but I don't know whether it is sound.

It would appear that Prittgensteinian hinge epistemology preserves epistemic closure in letter but not in spirit. ${ }^{19}$

One might try to avoid the problem here by denying that I know the conditional premise above. But that is to deny that I know an obvious a priori truth and thus it makes this proposed solution to the problem of skepticism even more radically skeptical than it already was.

\section{Conclusion}

While it is not the most extreme version out there, the view Pritchard offers is nonetheless a very radical form of skepticism. This makes it a poor fit with epistemological disjunctivism. And, although the view does not deny any plausible epistemic closure principles, it ends up entailing the same kinds of absurdities that befoul the views that do.

19 The examples involving validity and soundness are what I call "logical abominations". For a discussion of how this sort of abominable conjunction plagues Dretske's account of knowledge see Veber (2013).

Manuscrito - Rev. Int. Fil. Campinas, v. 41, n. 1, pp. 115-165, jan.-mar. 2018. 


\section{Rodrigo Borges - On Pritchard's 'Epistemic Angst'}

'Epistemic Angst' (Pritchard, 2016) ${ }^{20}$ is yet another display of Duncan Pritchard's epistemological breadth and insight. The subtitle of the book gives its readers, a clue of the epistemological trouble they are in with Pritchard latest offering -'Radical Skepticism and the Groundlessness of Our Believing.' The message is clear: the book is not for the epistemologically faint of heart. And Pritchard faithfully delivers on this promise: first, he concedes so much to the skeptic he makes us fear we will not be able to ever defeat her; second, he provides direct rebuttals of skeptical arguments in their strongest form. The first move highlights how radical the skeptical problem Pritchard is considering actually is. If the skeptic is right, our empirical beliefs are completely devoid of any actual (as opposed to apparent) rational basis - it is a big philosophical deal. Pritchard claims the skeptical threat actually causes him, personally, to feel angst. As readers, we believe him, and we are given no reason to doubt the seriousness of the matter anywhere in book. Pritchard's attack on the two skeptical arguments he considers (i.e., a closure-based argument and an underdetermination-based argument), on the other hand, seems to be not only proportional to the scope of the skeptical threat, but it also seems to go as deep as it is necessary in order to extirpate those threats. The scope of either threat is nothing short of all our empirical knowledge and it has two different sources: the insular nature of the reasons we have for our empirical beliefs and the universal nature of the rational evaluation of beliefs. According to the first source of skepticism, the reasons we have for our empirical beliefs are insulated from the external world in that we may have them even if what we believe about the external world is false. This source fuels the underdetermination-based argument for skepticism. According to the second source of skepticism, on the other hand, our practice of assessing the epistemic worth of our beliefs is fully general - any belief may be assessed along those lines. This source fuels the closure-based argument for skepticism.

For Pritchard, the way to stop the underdetermination-based argument of skepticism is to show that the common sense credentials of this idea are rotten. Epistemological disjunctivism, the thesis that the rational support for one's empirical belief is factive and open to reflective access, is the antidote to this version of the problem, we are told. As for the closure-based argument for skepticism, the

${ }^{20}$ Unless otherwise noted, all page references are to this work. 
antidote, says Pritchard, is to be found in Wittgenstein's insights about the structure of rationalevaluations developed in On Certainty (1969).

Each anti-skeptical strategy seeks to undercut the skeptical threat by showing that the paradox they engender is not really a paradox. This type of strategy is to be preferred to an overriding strategy in which one seeks to show that there is a reason independent of the paradox itself to disregard one or more of the claims in the paradoxical set. As a theoretical bonus, Pritchard seeks to marry both antiskeptical strategies by arguing that what seems immodest about the disjunctivist's partof thestory (i.e., herinsistencethatwehavereflectiveaccess to the factive grounds of our empirical beliefs) is in reality a feature of rational evaluation in general - namely, that all rational evaluation presupposes some basic commitments that are themselves immune to (rational) evaluation (i.e., Wittgenstein's 'hinge propositions'). He calls this theoretical marriage the biscopic proposal.

In addition to outlining the main argumentative threads of Epistemic Angst, I hope the tone of the previous paragraphs also imparts the fact that I am, on the whole, sympathetic to Pritchard's take on the issue of radical skepticism. I am also truly impressed by the ambition of Pritchard's project and the philosophical dexterity and elegance with which he manages to make the whole thing hang together. I do, however, have some concerns about Pritchard's rejection of what he calls 'modest externalism' (a version of process reliabilism). In the remainder of this paper I will present those concerns.

Pritchard considers a simple form of process reliabilism as a response to the closure-based versions of the skeptical paradox and argues that it faces a dilemma. ${ }^{21}$ Which hornimpales the externalist depends on whether herview takes a more or less 'revisionist' form. I will argue that this dilemma against the externalist does not succeed; at least not in the version featured in the book.

Pritchard discusses two versions of the skeptical paradox based on the closure principle: one suggesting skepticism about knowledge and another suggesting skepticism about the rational grounding of such knowledge. Here's the paradoxicalsetofclaimsaboutknowledge:

\footnotetext{
${ }^{21} \mathrm{He}$ also considers what is roughly the same form of process reliabilism as a response to the underdetermination-based version of the skeptical paradox (p.32-6) and says it too is impaled by this dilemma.
}

Manuscrito - Rev. Int. Fil. Campinas, v. 41, n. 1, pp. 115-165, jan.-mar. 2018. 


\section{(CKV)}

(I) One is unable to know the denials of radical skeptical hypotheses.

(II) The closure principle for knowledge (i.e., If $\mathrm{S}$ knows that $\mathrm{p}$, and $\mathrm{S}$ competently deduces from $\mathrm{p}$ that $\mathrm{q}$, thereby forming a belief that $\mathrm{q}$ on this basis while retaining her knowledge that $\mathrm{p}$, then $\mathrm{S}$ knows that $\mathrm{q})$.

(III) One has widespread everyday knowledge.

One of the responses to (CKV) Pritchard (p.20) considers is a simple version of externalism, process reliabilism, which says that (I) should be rejected because our beliefs in the denial of radical skeptical hypotheses are caused by a (conditionally) reliable belief forming method (i.e., deduction from empirical proposition we also know). What is more, according to the externalist this is enough to give us knowledge of the denial of radical skeptical hypotheses. According to her, this knowledge does not require rationality, which is itself understood as requiring reflective access to what grounds one's knowledge. This view contrasts with internalist views that take knowledge to be rationally grounded and to require that the subject have reflective access to what grounds her knowledge. Pritchard argues that theinternalisthas an advantage over the externalistbe- cause people intuitively think that knowledge is rationally grounded. Hence, he proposes that the externalist response to (CKV) faces the following dilemma necessitated by this intuition concerning the rational grounding of knowledge

(p.21-25).

(D1) Either the externalist endorses a modest form of revisionism of our epistemic practices or

(D2) or the externalist endorses a far more radical form of revisionism of our epistemic practices.

According to Pritchard, the externalist who embraces (D1), ends up offering 'no response at all to the skeptical problem.' The externalist who embraces (D2), on the other hand, ends up with a view that is 'so discontinuous with our ordinary epistemic practices, that even the most ardent proponent of epistemic externalism would find it unpalatable' (p.21-2). Following Pritchard, call the type of externalism implicated in (D1) 'modest externalism' and the type of external- ism implicated in (D2) 'immodestexternalism.'

I am not sure I fully understand what Pritchard means by 'epistemic practice' 
in this context but he seems to be referring to our inclination to see all in- stances of knowledge as being rationally grounded and for those grounds to be reflectively accessible to the subject. In that sense, modest externalism endorses a modest form of revisionism of this practice because although it accepts the idea that all instances of knowledge are rationally grounded, it rejects the idea that those grounds are reflectivelyaccessible to thesubject. Theimmodestexternalist, in turn, rejects both ideas relating knowledge and rational support in the relevant epistemic practicehence, the accusation that this view is utterly 'discontinuous with our ordinary epistemic practices.' But, if the problem with immodest externalism is one of rejecting a central intuition about knowledge, what is the problem with modest externalism? Here is the first difficulty I have with the dilemma for externalism: I am not sure what the problem is supposed to be for modest externalism. Pritchard says that the problem with modest external- ism is that it cannot handle the following version of the skeptical paradox for rationallygroundedknowledge:

\section{(CRV)}

(I) Oneisunabletohaverationallygroundedknowledgeofthedenials of radical skeptical hypotheses.

(II) The closureprinciple forrationallygrounded knowledge(i.e., IfShas rationally grounded knowledge that $\mathrm{p}$, and $\mathrm{S}$ competently deduces from $\mathrm{p}$ that q, thereby forming a belief that q on this basis while retaining her rationally grounded knowledge that $\mathrm{p}$, then $\mathrm{S}$ has rationally grounded knowledge that q).

(III) Onehaswidespreadrationallygroundedeverydayknowledge.

Now, I understand, of course, that (CRV) is paradoxical, but I do not see why modest externalism has any problem handling it. Given that the modest externalist thinks that all knowledge is rationally grounded, it follows that modest externalism handles (CRV) if and only if it handles (CKV): since there is no knowledge that is not rationally grounded, according to the modest externalist, (CRV) does not present modest externalism with a challenge that was not already present in (CKV). As far as modest externalism is concerned, both paradoxes stand or fall together. So, (CRV) does not seem to present modest externalism with a problem it cannot answer; at least no more than (CKV) does, and the modest externalist had already offered an answer to (CKV). One may disagree with modest externalist's claim that reliably deducing the denial of skeptical hypotheses from other propositions one knows rationally grounds one's

Manuscrito - Rev. Int. Fil. Campinas, v. 41, n. 1, pp. 115-165, jan.-mar. 2018. 
knowledge in the denial of those hypotheses, but we cannot say that the modest externalist has nothing to say about (CRV).

Perhaps what Pritchard means is this. The notion of rationality featured in (CRV) presupposes the thesis about rational support that moderate externalists reject (i.e., the thesis according to which the rational grounds for knowledge need to be reflectively accessible to the subject), and that is why moderate externalism has nothing to say about (CRV). ${ }^{22}$ In so far as we do not make being able to reflectively access one's rational grounds a necessary condition on having those grounds (more on that later), this interpretation of (D1) would distinguish (CRV) from $(\mathrm{CKV})$ and open up logical space for the claim that modest external- ism fails to solve the skeptical paradox presented by (CRV) even if itsuccessfully takes care of the skeptical paradox presented by (CKV). Unfortunately, this version of (D1) suffers with its own problems, leaving the modest externalist with little or no reason to worry about the soundness of her anti-skeptical strategy.

What does it mean, exactly, to say that rational grounds for knowledge need to be reflectively accessible to the subject in order for his knowledge to count as rationally grounded? As far as I can see, there is no answer to this question in 'Epistemic Angst.' Moreover, a quick look at the obvious ways in which one might cash out this notion lead to less than encouraging results for Pritchard's case against moderate externalism. For one thing, having a ground reflectively accessible to one is neither clearly necessary nor clearly sufficient for knowing. It is a well-known cognitive trait of highly skilled professionals that their skill allows them to know things even though they are not able to reflectively access any groundsforthisknowledge. Forinstance, veteranfirefighters cansometimes know a room in a burning building will collapse right before it does but they have no idea why they think that it would; they of course know that this knowledge is an indirect result of their training but there is no specific ground they can reflectively access and that rationally grounds their knowledge. ${ }^{23}$ This suggests that being able to access one's grounds reflectively is not necessary for rationally grounded

22 Compare (p.33), where Pritchard comes very close to saying that our epistemic practices presuppose theidea that our rational grounds for knowledge are reflectively accessible.

${ }^{23}$ Note that I am not saying that there is no ground on which the firefighter's knowledge is based. The point is merely that he has no reflective access to that ground. See (Kahneman, 2011, ch.22) for a review and discussion of the relevant experimental findings in psychology, including the research with firefighters.

Manuscrito - Rev. Int. Fil. Campinas, v. 41, n. 1, pp. 115-165, jan.-mar. 2018. 
knowledge. Although the non-sufficiency of a condition is always hard to prove (one can always argue that the target condition is satisfied but some other condition isn't), some cases may be plausibly taken to suggest that having reflective access to what rationally grounds one's belief add nothing (or almost nothing) to the epistemic status of one's belief. For instance, suppose I believe truly (but before I check the results) that my lottery ticket lost solely on the basis of the odds of that happening. One might plausibly say that I have a non-gettiered justified true belief that my ticket lost. What would accessing my grounds via reflectionadd, epistemically speaking, to this belief? Itseems thatit would not move me any closer to knowing that my ticket lost or to improving the epistemic status of this belief in any noticeable way. ${ }^{24}$

One may insist that, even if this is right, it is still true that in the contexts in which the skeptical paradoxes are salient, one counts as having rationally grounded knowledge only if one is able to reflectively access one's grounds. In fact, it might be said that having a rationally grounded knowledge and being able to reflectively access the ground of one's knowledge are one and the same thing in those contexts (p.33). Would this reply help Pritchard's case against modest external- ism? It's not clear that it would. For one thing, we might respond by saying that identifying the two notions, in any context, conflates two different things: it conflates $S$ has a ground/ reason for $p$ with $S$ is in a position to know she has a ground/ reason for $p$. Granted, being in a position to know that something is one's ground for knowing $\mathrm{p}$ might (sometimes) be an improvement on merely knowing that $\mathrm{p}$ (perhaps it puts one in a better position to fend off misleading evidence), ${ }^{25}$ but that is different from saying that the latter is identical to the for- mer. To deny that would be like saying that I have no money in my bank account because I do not have one million dollars in my bank account. The latter is quite an improvement on my current bank account (actually, it's a huge improvement on any bank account I have ever had!), but they are not the same thing.

There is also a more basic issue lurking in the background here. The

\begin{abstract}
${ }^{24} 5$ Pritchard's way of dealing with lottery cases such as this is, of course, to say that the possible world in which my ticket won is close enough to the actual world so as to make my true belief in the actual world unsafe. As far as I can see this way of looking at things is compatible with saying that I have a un-gettiered justified true belief in the proposition that my ticket lost. See, e.g., Pritchard (2012), Pritchard (2014).
\end{abstract}

${ }^{25}$ See (Borges, 2015) for the claim that such an improvement exists.

Manuscrito - Rev. Int. Fil. Campinas, v. 41, n. 1, pp. 115-165, jan.-mar. 2018. 
suggestion is that knowledge is rationally grounded if the grounds are reflectively accessible to the subject. This way of talking about rational grounds for knowledge raises a few questions. For example, I think my (soon to be) three-year-old son sees, and thereby knows, that the toy in his hands is green - we practice naming the colors of objects everyday, and he's pretty good at it. Moreover, I think his knowledge is rationally grounded - that's what reliable vision and a rudimentary (but reliable) mastery of color concepts will give you when used properly. However, I am quite certain that the rational grounds of my son's knowledge are not reflectively accessible to him. Heis not able to use complicated concept such as reliability or even seeing in introspection; he is not even able to answer simple questions such as ' $\mathrm{Can}$ the toy be green and red all over?', a question any adult who masters those color concepts is capable of using in reflection. So, it seems that unless we want to say (quite implausibly, I think) that my son's knowledge is not rationally grounded, we should not identify the question of my son's knowledge being rationally grounded with himbeingabletoreflectivelyaccess the rational grounds of his knowledge. ${ }^{26}$

But maybe this is too fast. It may be argued that Pritchard's goal is to fend off skepticism with respect to mature, or adult knowledge; the requirement on knowledge, that its grounds are reflectively accessible, does not apply to children or to supermarket doors. ${ }^{27}$ Fair enough, but now the question is: does this requirement apply to mature, sophisticated adult knowledge? Before we look for an answer to this question, however, we need to make a couple of points explicit. In order to succeed, the contention that rationally grounded knowledge requires grounds to be reflectively accessible needs to satisfy two constraints. First, the grounds knowers are able to reflectively access must actually rationalize their knowledge. If this constraint on what grounds need to be reflectively accessible

${ }^{26}$ One may be inclined to reply in the following way. 'Although your son is not able now to
reflectively access his grounds for knowing that the toy in his hands is green, he will
eventually be able to do that in the future and that is enough for his knowledge to count as
rationally grounded now.' The idea here is that my son counts as being able to reflectively
access the grounds for his knowledge because he will have what it takes to access those grounds
in the future, even if he does not have what it takes to do that right now. I do not think this
suggestion works, however. It seems clear that the knowledge my son has today about the
color of his toy is rationally grounded even if he were to die tomorrow, thus thwarting his
hopes of havingreflective access toanythingin the future. ${ }^{27}$ Compare p.22. 
were not in place, then one would have to say, implausibly, that it is possible for $\mathrm{S}$ to have rationally grounded knowledge that $\mathrm{p}$ even though she has reflective access not to ground, g, that actually rationalizes her knowledge, but only to a poor ground, $\mathrm{g}^{*}$, that does not rationalize $\mathrm{p}$ for her. In other words, unless this constraint is in place, there is no point in insisting that reflectively accessing those grounds is what rationalizes one's knowledge. Second, in order to count as having rationally grounded knowledge $S$ must be disposed, when in the right circumstances, to reflect on the grounds of her knowledge in an epistemically appropriate way: the fact that I am able to reflectively access that which grounds my knowledge cannot contribute to this knowledge's rationality if I am disposed to reflectively access those grounds using, say, motivated reasoning or guesswork. With these constraints in mind, we can return to the issue of how to think about therequirementof reflectiveaccessibilityon (matureoradult) knowledge.

One idea is to say that one is able to reflectively access one's grounds for knowing if one satisfied some sort of counterfactual condition such as if $S$ were to reflect on herknowledgethatp, shewouldtake gto be hergroundforbelieving that $p$. The worry with this sort of analysis of reflectively accessible grounds is that it might fall prey to what Robert Shope (1978) called the 'conditional fallacy. ${ }^{28}$ For example, one might devise a case where, although $\mathrm{S}$ actually knows that $\mathrm{p}$, if she were to reflect on her grounds for knowing, she would get so nervous that she would have a heart attack and die instantly without ever accessing the grounds rationalizing her knowledge. The suggested counterfactual condition is not satisfied, but $\mathrm{S}$ would still know that $\mathrm{p}$.

Another idea is to say that a ground, $g$, is reflectively accessible to $S$ for her knowledgethatponlyifanidealagent, $S^{*}$, inS'ssituation, wouldhavereflective access to g. This, however, would be hardly an improvement on the first suggestion, given that we need a positive reason to believe that the grounds that are available to a perfectly rational being will be the same grounds that are available to less-thanperfect beings like us. In fact, there is reason to think that there is at most partial overlap between the set of grounds available to a perfectly rational beingand the set ofgroundsavailabletoaless-than-perfectrationalbeinglikeus. To see that, consider the following argument adapted from (Williamson, 2000, p.210). Let p be a logical truth and for it to be very probable on our evidence that no one has greatcredence in p. Let h be: no one has great credence in $\mathrm{p}$. It follows that $\mathrm{h}$ is very probable on our

28 See (Bonevac, Dever, \& Sosa, 2006) for a recent survey of the literature on the conditional fallacy.

Manuscrito - Rev. Int. Fil. Campinas, v. 41, n. 1, pp. 115-165, jan.-mar. 2018. 
evidence. In contrast to our epistemic situation, a perfectly rational being must give high credence to $\mathrm{p},{ }^{29}$ she must be aware of doing so, and, as a result, she must also give very low credence to $h$ and to $(p \rightarrow h)$. But, if this is right, then this being's evidence about it's own mental states would be different from ours, showing that perfectly rational beings cannot have the same reflectively accessible grounds we, less-than-perfectbeings, have. ${ }^{30}$

In sum, it might be argued that Pritchard's dilemma for modest externalism is at bestinconclusive and, at worst, flawed. In particular, it is notentirely clear thatwe can have a serviceable enough account of reflectively accessible ground to do the work Pritchard needs it to do in his case against modest externalism. Moreover, some might argue that this difficulty makes the immodest take on externalism considerablymoreattractivethan Pritchard'sownestimationwould leadus to believe. However, assessing theplausibilityof thislatterclaimis atask to be pursued perhaps tomorrow, but not today. ${ }^{31}$

${ }^{29}$ This follows from the axioms of the probability calculus and the popular assumption that epistemically ideal beings conform their credences to those axioms.

30 The requirement of reflective accessibility of grounds on rationally grounded knowledge might also suffer from what Alvin Goldman called 'the problem of forgotten evidence' Goldman (1999). For some ps, if I come to acquire rationally grounded knowledge that $\mathrm{p}$ in virtue of ground $\mathrm{g}$, at time $\mathrm{t}$, then I can still have a rationally grounded knowledge that $\mathrm{p}$ at a later time, $\mathrm{t}^{*}$, when I have forgotten about $\mathrm{g}$. But, if one has rationally grounded knowledge only if one can access the grounds in virtue of which one believes rationally, then it is not possible for one to have rationally grounded knowledge that $\mathrm{p}$ if one has forgotten one's ground $-g$ is no longer accessible. Thus, the requirement of reflective accessibility of grounds on rationally grounded knowledge seems to reduce (perhaps substantially) the scope of ordinary knowledge if, as Goldman suggests, we forget the grounds for much of what we know.

${ }^{31}$ Gregory Gaboardy, Felipe Medeiros, and Mike Veber have all read and commented on different drafts of this paper. I am grateful for their support and insight. I am solely responsible forany mistakes that may exist, of course.

Manuscrito-Rev. Int. Fil. Campinas, v. 41, n. 1, pp. 115-165, jan.-mar. 2018. 


\section{Duncan Pritchard - Responses to My Commentators}

\section{Introductory remarks.}

I would like to thank my commentators for taking the time to engage with my monograph. The dread of an author - a sensible author, at any rate-is not directed at the thought of possible critical scrutiny, but rather at the possibility that no-one takes any interest in the work whatsoever. In that spirit, I am delighted that there are philosophers out there keen to engage with my work, critically or otherwise.

\section{Response to Salvatore.}

Salvatore's first worry about my anti-sceptical proposal centres on the notion of epistemic vertigo that I introduce at the end of the book. As I make clear, my biscopic treatment of radical scepticism is of an undercutting variety, which means that the two (logically distinct, I claim) putative paradoxes that make up the puzzle are shown to not be genuine parades at all. That is, there is no fundamental tension within our everyday epistemic notions that the radical sceptic has exposed; rather, the sceptical problem, on both of its formulations, is trading on contentious theoretical claims that we should abandon. This means that there is no sceptical problem to contend with, and hence no need for epistemic angst.

Even so, I do not claim that resolving the sceptical problem returns us to a state of epistemic innocence, on a par with those who are ignorant of the problem, and that is why I introduce the notion of epistemic vertigo. The crux of the matter is that in our everyday inquiries we never become aware of the fundamental role that our arational hinge commitments play in our localised rational evaluations. As Wittgenstein puts it, they simply "lie apart from the route travelled by inquiry." (OC, $\left.\iint 88\right)^{32}$ As such, although our system of rational evaluation is in its nature local, this is never made explicit to us. By engaging with the sceptical problem, however, even in such a way as to realise why this problem is illusory, one inevitably becomes aware of the role that

32 Note that I am referring to Wittgenstein's (1969) On Certainty as 'OC'. 
hinge commitments play in our system of rational evaluations, and hence one also becomes aware of the localised nature of these evaluations. In a sense, a kind of epistemic ascent has occurred, whereby we're viewing our epistemic practices from a detached (indeed, I would say unnatural) perspective. I think it is this epistemic ascent that leads to the vertigo, in that even once we realise that the sceptical problem is illusory - and, in particular, that it is in the nature of rational evaluations that they occur relative to a backdrop of arational hinge commitments, and hence are essentially local—we might still experience a vestige of anxiety about our epistemic position.

It's important to reflect on the terminology in play here, however. In particular, the use of the phobic term 'vertigo' is very deliberate (the pedants amongst us can substitute 'acrophobia' here if they wish). The idea is that if there is an anxiety remaining, it is explicitly phobic because it will run counter to what we know full well to be the case. That is, just as one can be high up and experience vertigo even though one knows full well that one is not in danger, so one can reflect on one's epistemic position in a certain way (i.e., via the epistemic ascent), and experience epistemic vertigo, even while knowing full well that there is no epistemic insecurity in play (and thus no cause for epistemic angst).

Salvatore thinks that the anxiety here is more than just a phobic response, however, in that he maintains that we should feel epistemic anxiety once we realise that our practices of rational evaluation are not full general, but rather presuppose arational hinge commitments. I think this is a mistake. In particular, it ignores the very important aspect of the Wittgensteinian picture that it is in the nature of our system of rational evaluation that it is essentially local in this way. As Wittgenstein emphasises at a number of junctures, this is not an incidental feature of our rational practices, but rather a matter of (as he puts it) of logic (see, e.g., OC, \$\$341-43).

Moreover, we also need to remember here that the Wittgensteinian line I take is but one part of the biscopic treatment of radical scepticism that I offer. In particular, the other key aspect to this treatment of radical scepticism- the appeal to epistemological disjunctivism - is vitally important to understanding why my proposal is not a 'sceptical solution' to the problem..$^{33}$ This is because it

33 For further discussion of epistemological disjunctivism in its own right, see Pritchard (2012b). 
is this component of the biscopic stance that ensures that many of our everyday reasons can be factive, and thus that our beliefs enjoy far stronger rational support than we hitherto supposed. As I explain in the book, the Wittgensteinian and epistemological disjunctivist lines, far from being competing approaches, are in fact mutually supporting, in that each view becomes more plausible when combined with the other. So, for example, it is far easier to accept the idea that rational evaluation is of its nature local if the rational support one's core everyday beliefs enjoy are factive.

Salvatore's second critical point concerns epistemic relativism. In particular, he argues that by embracing hinge commitments I will be stuck with a radical kind of epistemic relativism that I have elsewhere argued is malignant (more modest forms of epistemic relativism are, I would argue, benign). ${ }^{34}$ This is epistemic relativism which is committed to there being radically incommensurate systems of rational evaluation, such that there can be disagreements between members of these two systems that could never, even in principle, be rationally resolved.

Salvatore clearly holds that if there can be any divergence between the hinge commitments that we endorse, then radical epistemic incommensurability immediately follows. But this is far too quick. In fact, my account of hinge commitments is arguably unique among accounts of this kind in being able to avoid this entailment. Remember that on my view all hinge commitments are expressions of the general über hinge commitment that we all share-viz;, a visceral, arational certainty that we are not radically and fundamentally in error in our beliefs. Once we understand this point, it becomes apparent that our hinge commitments are not nearly as heterogeneous as we might have previously thought. For example, it may be a hinge commitment of mine that I speak English, while it is a hinge commitment of someone raised in China that they speak Chinese. This is hardly a divergence in our hinge commitments, however, but rather different expressions of effectively the same underlying hinge commitment regarding the language that we speak, common to both of us. It is just that our different circumstances-our geographical location in this case-means that the über hinge commitment in play manifests itself with a specific hinge commitment with a slightly different content. The same goes for

34 See Pritchard (2009; 2010).

Manuscrito - Rev. Int. Fil. Campinas, v. 41, n. 1, pp. 115-165, jan.-mar. 2018. 
many of the familiar examples we use (e.g., my name is such-and-such, and so on).

This is not to deny that there can be genuine divergences in one's hinge commitments. Indeed, I suspect religious conviction might be a case in point, an issue I've explored elsewhere. ${ }^{35}$ The point is rather to emphasise that a lot of what may at first glance look like genuine divergence in our hinge commitments is in fact superficial. Moreover, even if it is true that there is some genuine divergence in our hinge commitments, radical epistemic incommensurability does not immediately follow.

To see this we need to remember a further feature of my account of hinge commitments, again drawn from Wittgenstein's own remarks. This is the idea, which crops up throughout On Certainty, that in order to occupy the space of reasons at all, one "must already judge in conformity with mankind." (OC, \$156) Wittgenstein clearly had in mind a philosophical viewpoint that we would now associate with the holistic form of content externalism later espoused by Donald Davidson. ${ }^{36}$ This is a conception of content such that radically departing from the fundamental commitments of those around us is impossible because in such circumstances one would fail to articulate meaningful thoughts. It follows that we necessarily have substantial overlaps in our hinge commitments with those around us.

Incidentally, I think this is the reason why the river-bed analogy (OC, $\$ \int 96-$ 99) that Wittgenstein uses in describing our hinge commitments is the most effective at capturing what he's after. Whereas the 'hinge' metaphor brings with it the idea of optionality (one can move one's hinges at will after all), which is something Wittgenstein clearly doesn't want, the river-bed analogy instead reminds us of Wittgenstein's essential communitarianism-i.e., that we are all

35 See in particular my defence of a distinctive Wittgensteinian stance as regards the epistemology of religious belief — which I call quasi-fideism — in Pritchard (2011; 2105; 2017; forthcoming).

36 See, for example, Davidson (1983 [1986]). I explore Davidson's own stance on radical scepticism in Pritchard (2013).

Manuscrito-Rev. Int. Fil. Campinas, v. 41, n. 1, pp. 115-165, jan.-mar. 2018. 
being swept along in this river together. ${ }^{37}$ Yes, there can be change over time in one's hinge commitments, just as in the metaphor what was once part of the river-bed can over time become part of the river, and vice versa, but this change will inevitably be gradual and piecemeal.

Moreover, as I explain in the book, on my theory of hinge commitments, we can account how disagreements arising out of modest divergences in one's hinge commitments can be resolved rationally. This is because although one's hinge commitments are not directly responsive to rational considerations, they are indirectly responsive to such considerations. This follows from the fact that individual hinge commitments are expressions of the more general über hinge commitment. The path from the former to the latter goes via your wider set of beliefs. (Remember here, by the way, that hinge commitments are not beliefs, at least not in the sense of that propositional attitude which is a constituent part of rationally grounded knowledge anyway, but rather a distinct kind of propositional attitude). This is why it is a hinge commitment in normal conditions to think that you have two hands, but not when you are coming around after having major surgery on your hands that might have led to one of them being removed. Once we recognise this point, however, then it becomes clear how there can be rational ways of changing someone's hinge commitments over time. In particular, what you need to do is get them to change their wider set of beliefs. If you can do that, then over time you can change their hinge commitments too.

In fact, rather than my view facing a problem with epistemic relativism, I think it instead gives us practical advice about how to deal with some of the most apparently intractable disputes of our day. Take the dispute between evolutionary theorists and creationists. Once we recognise that the source of this disagreement are very fundamental prior commitments, it becomes clear that there is simply no point in either side trying to convince the other 'headon'. That is only going to lead to lots of hot air and neither side budging an inch. Rather, the way to deal with such disagreements is to go 'side-on'. What I mean by this is that one should seek out areas of agreement and work on maximising that. In doing so, one can gradually inch one's adversary towards

37 If you think the idea of Wittgenstein as embodying some kind of communitarian spirit is implausible, then I urge you to read Tanesini's (2004) wonderful, and unjustly neglected, book on his work.

Manuscrito-Rev. Int. Fil. Campinas, v. 41, n. 1, pp. 115-165, jan.-mar. 2018. 
one's side. Of course, this won't be an easy process, and the practical impediments might be insuperable. But I think that this is entirely to be expected-whoever thought that rationally resolving such deep disagreements would be easy? The key point, however, is that the practical difficulty of rationally resolving deep disagreements is philosophically miles apart from the claim that Salvatore is trying to pin on my view-vir., that such disagreements could never, even in principle, be rationally resolved.

I want to close with a very small point of clarification, which is that Salvatore mischaracterises my view at one point, in that he attributes to me a non-propositional account of hinge commitments. This is not in fact my view. Rather, I think that our hinge commitments can be thought of in terms of propositional attitudes, while at the same time accommodating the kinds of considerations that lead others, such as Salvatore himself, to opt for a nonpropositional view. ${ }^{38}$ Moreover, this misattribution, while minor, has at least one unfortunate knock-on effect, which is that Salvatore also mischaracterises why I hold that hinge commitments are not beliefs (in the specific sense of 'belief outlined above anyway). Salvatore thinks that this follows from my commitment to a non-propositional account of hinge commitments, but instead it in fact follows from the distinctive kind of propositional attitude that is on display with regard to our hinge commitments. In particular, I argue that a propositional attitude of endorsement of $p$ which could co-exist with the recognition that one has no rational basis for thinking $p$ true is not a belief. Given how I describe, following Wittgenstein, hinge commitments, it follows that they cannot be beliefs. I think this point that hinge commitments are not beliefs is very important, as a failure to distinguish between these two kinds of propositional attitude has created all kinds of problems for hinge epistemologies, not least in that it has obscured the manner in which such an epistemology can deal with the closure-based formulation of radical scepticism without resorting to denying the closure principle.

38 See also Moyal-Sharrock (2004).

Manuscrito - Rev. Int. Fil. Campinas, v. 41, n. 1, pp. 115-165, jan.-mar. 2018. 


\section{Response to Veber.}

Veder's first concern about my view is surely one that many philosophers would have when they first come across it. For I really am saying that one key move we need to make in order to resolve the radical sceptical problem is to recognise that our hinge commitments are not in the market for rationally grounded knowledge. It follows that there are many claims of which we are optimally certain, such as that one has hands, which are not known. And that can seem a remarkable thesis at first blush. As Veder once put to me in conversation (and I am here paraphrasing), 'Wait a minute, you're saying that your response to the problem of radical scepticism is to say that you don't know you have hands?'3 3

But we need to tread a bit more carefully here. For notice that it is rather misleading to gloss my view as merely the claim that our hinge commitments are unknown. This is because there is an important sense in which they are neither known nor unknown. What I mean by this is that the whole point of the Wittgensteinian line I take is that some of our most basic commitments are simply not in the market for knowledge. As such, to simply say that they are unknown is misleading since it implies ignorance on our part, as if there is something that could have been known and we failed to know it. But that's not our epistemic relationship to these commitments at all, since once we understand the Wittgensteinian picture of the structure of rational evaluation we thereby realise that there is no coherent sense of our hinge commitments being the kinds of things that could have been known. I think Stanley Cavell (1979, 241) expressed this point very nicely when he noted how, for Wittgenstein, the "human creature's basis in the world as a whole, its relation to the world as such, is not that of knowing, anyway not what we think of as knowing." The key thing is to understand why recognising this is part of the resolution of the sceptical problem, rather than a capitulation to it. ${ }^{40}$

39 This exchange took place at a 2014 summer school hosted by the University of Cologne that was devoted to (what was then) the unpublished manuscript of Epistemic Angst.

40 Incidentally, various philosophers over the years-Marie McGinn, Michael Williams, Pen Maddy and Ram Neta spring to mind in this regard-have urged me to water-down this part of my view and claim that our hinge commitments 
It is also important to remember in this regard that, contrary to what Veber says, we do not ordinarily take it as given that we know our hinge commitments. In fact, as Wittgenstein deftly illustrates, we don't ordinarily consider them at all, but they are rather part of the tacit background relative to we consider other things. In fact, it takes a specifically philosophical context to introduce consideration of the hinge commitments (i.e., of the relevant propositional content, qua hinge commitment; the reason for this caveat will become apparent in a moment). Indeed, while there are some unusual everyday contexts where we might consider the relevant propositional content at issue, this is invariably a context where it has temporarily ceased to be a hinge commitment, in which case it is then in the market for knowledge. I gave one such example above-in coming around from major surgery on one's hands, it is not a hinge commitment that one has hands, and that's why you can come to know this by seeing your hands. Over time, however, it will drift back into the backgrounds and become a hinge commitment again, at which point it will again no longer be in the market for knowledge (but also something that you won't ordinarily even consider).

Veber's second concern was the compatibility of epistemological disjunctivism and my Wittgensteinian account of hinge commitments. According to the former, in paradigmatic cases of perceptual knowledge one enjoys reflectively accessible factive reasons in support of one's beliefs. Veber finds this puzzling because he takes our hinge commitments to capture paradigmatic cases of knowledge, and of course I claim that they are not even in the market for knowledge.

can be knowledge, but just not rationally grounded knowledge. While this stance could be made to be broadly consistent with my proposal, I have some concerns. For one thing, while I am epistemic externalist about knowledge, and hence am willing to allow that one can have knowledge in the absence of reflectively accessible rational support, I nonetheless think that some kind of virtue-theoretic story needs to be told about where this knowledge comes from, and I struggle to see how such a story would pan out in the case of our hinge commitments. (Incidentally, the reader who is interested in my wider theory of knowledge-known as anti-luck/anti-risk virtue epistemology-should consult Pritchard (2012a; 2016)).

Manuscrito-Rev. Int. Fil. Campinas, v. 41, n. 1, pp. 115-165, jan.-mar. 2018. 
There is in fact no tension here, as is clear if one looks again at how I characterise paradigmatic cases in my description of epistemological disjunctivism. This is because I make crystal clear that I am concerned with cases of perceptual knowledge (and thus of perceptual belief), neither of which, I argue, applies to our hinge commitments. I noted above that I don't think we do ordinarily think of our hinge commitment as known, contra Veber. (Philosophers might think of them as paradigmatically known, but that's a different matter). A fortiori, on my view it is also the case that I don't think we ordinarily regard them as paradigmatic examples of knowledge either. So the putative tension with our ordinary ways of thinking about these epistemic matters is illusory.

Veber's third criticism is especially interesting. In the book I note that my view might seem to be subject to some version of the 'abominable conjunction' view that is posed for those who deny the closure principle. ${ }^{41}$ The thought is that there will be propositions that I know, and which I know straightforwardly entail the denials of radical sceptical hypotheses, but where I fail to know the latter. Thus we get statements like 'I know I have hands, but I don't know that I'm not a handless brain-in-a-vat' that, on the face of it, look very dubious.

Now I don't deny the closure principle, but I do argue that our hinge commitments, including our hinge commitment that we are not the victims of radical sceptical scenarios, are not in the market for knowledge, so it may seem like I should face a variant of this puzzle (although the example just cited won't work on my view, as the entailment in question is from one unknowable hinge commitment to another unknowable hinge commitment). In the book I argued that such conjunctions cease to be puzzling once we have the perspective provided by the Wittgensteinian account of hinge commitments. For one thing, such conjunctions are not going to be uttered in ordinary contexts, but only in specialised contexts where we are doing philosophy, so we should immediately be on the alert that they should not simply be taken at face value. Moreover, once we have the Wittgensteinian account in play, it becomes apparent that what such conjunctions are in fact expressing is (what we have seen to be) the harmless fact that our everyday beliefs, which are in the market for knowledge, can entail propositions that we are hinge committed to, and hence which aren't

41 For an early statement of this worry in these specific terms, see DeRose (1995).

Manuscrito - Rev. Int. Fil. Campinas, v. 41, n. 1, pp. 115-165, jan.-mar. 2018. 
in the market for knowledge. Remember too that it's not as if in saying that the hinge commitments aren't known that there is anything that we are ignorant of here, much less are we indicating that we aren't committed to their truth (in fact, we are optimally certain of it).

Veber offers a nice twist on the abominable conjunction objection by presenting an argument that involves a valid inference from an ordinary known belief to a hinge commitment. He argues that I am committed to holding both of the premises as being known (the one because it is ordinary known belief, the other because it is simply a conceptual truth), but also to treating the conclusion as unknown, because it concerns a hinge commitment. It follows, he claims, that I am committed to claiming that there can be valid arguments with true premises where I don't know whether the conclusion is true. And isn't that absurd?

I think this is far too quick. What would be absurd would be denying that a sound argument where you accept the premises commits you to the truth of the conclusion, but notice that this isn't what Veber is focussing upon, nor is it something that I would need to deny. Indeed, we are optimally certain of our hinge commitments, so of course we are committed to their truth, and that goes just as much when they feature as conclusions to sound arguments. This means that my view has no problem with the idea that sound arguments entail true conclusions, but only with the idea that when we have knowledge of the premises of a sound argument one must thereby have knowledge of the conclusion. I would certainly deny this claim, but I don't think that denying it commits one to absurdity. Indeed, far from it being an awkward consequence of my account of hinge commitments, it is in fact directly entailed by it, as where a sound argument entails a hinge commitment, it obviously cannot lead to knowledge of that conclusion.

I think the apparent awkwardness of the assertion that one can know the premises of a sound argument without knowing the conclusion can be explained away. In particular, in simply saying that one doesn't know the conclusion of a sound argument with known premises it can sound as if one is both not committed to the conclusion and that one is attributing ignorance of this conclusion to oneself (as if one could have known this proposition, but failed to). As we have seen, neither of these claims are true when it comes to our hinge commitments, and once we make this explicit, and explain the 
motivation for why the conclusion isn't known as part of a wider Wittgensteinian hinge epistemology, then no absurdity remains.

\section{Response to Borges}

Borges's main concern is to take issue with how I cast the radical sceptical problem in terms of rationally grounded knowledge. My rationale for this is that I take mature human knowledge to be clearly of the rationally grounded kind (indeed, I think that a lot of this knowledge is rationally grounded in factive reasons). That said, I am an epistemic externalist about knowledge, in that I don't think that all knowledge needs to be rationally grounded, albeit I'm an epistemic externalist of a modest stripe in that genuine knowledge that lacks a rational grounding is on my view rather peripheral (given that mature human knowledge tends to be of the rationally grounded kind). So I don't disagree with Borges that there are clear cases of knowledge that don't have rational support (like the veteran fire fighter case that he describes). Modest epistemic externalism is in contrast to a more radical form of epistemic externalism which claims that most of our knowledge, even of the mature human sort, is lacking in rational grounding. I dislike the latter position because I think it is too revisionary of our everyday epistemic practices, which clearly do treat most knowing subjects as operating within the space of reasons.

This distinction between modest and radical forms of epistemic externalism has a bearing on the sceptical problem in the following way. I take this puzzle, in its strongest form, to be claiming that we lack widespread rationally grounded knowledge. This means that a modest epistemic externalist like me cannot side-step the puzzle by being an epistemic externalist, as of course on this view one does have widespread rationally grounded knowledge. So nothing is gained from being an epistemic externalist in this sense when it comes to the sceptical problematic. In contrast, radical forms of epistemic externalism can try to evade the puzzle by claiming that most knowledge is not rationally grounded, and hence sceptical attacks on knowledge of this kind are irrelevant. I think there are lots of problems facing radical epistemic externalism of this kind, but the key issue for our current purposes is that any such strategy is inevitably going to be highly revisionary, and hence when applied to the sceptical problem will lead to an overriding rather than undercutting approach. 
In contrast, what I am offering is an undercutting anti-sceptical strategy, and I have argued that this is most definitely to be preferred.

With the foregoing in mind, let's look at Borges's objection. I fear that something important has gone wrong in his reading of me, since he claims that I am opposed to modest epistemic externalism of the kind just described, when in fact that is precisely my view about knowledge in general. ${ }^{42}$ Reading between the lines, I think the issue is that because I claim modest epistemic externalism, qua a form of epistemic externalism, cannot give us any resources to deal with a formulation of the sceptical problem in terms of rationally grounded knowledge Borges is inferring that I think there is something amiss with modest epistemic externalism itself. But that's not the case. In fact, as just explained, I endorse the view; it's just that I don't think it has any bearing on the sceptical problematic. 43

Things get murkier once Borges explains what he means by modest externalism, which is clearly not what I have in mind. He writes that this concerns the view that while all knowledge is rationally grounded, not all knowledge enjoys reflectively accessible rational grounds. In a domain like this, it is very much a term of art how one wishes to define one's terms, but for me, in Epistemic Angst at any rate, I am quite clear that by rational grounds I mean reflectively accessible rational grounds, so the distinction Borges wants to draw doesn't even arise on my view. This is not to say, of course, that one can't make this distinction, but Borges now needs to give us an account of what it means for knowledge to be rationally grounded, in a way that is relevant to the formulation of the sceptical paradox in hand (as my formulation isn't in

42 For those interested in my general account of knowledge, which I call antiluck virtue epistemology (or, increasingly, anti-risk virtue epistemology), see Pritchard, Millar \& Haddock (2010, chs. 1-4) and Pritchard (2012a; 2016).

43 In general, as I note in the précis of Epistemic Angst that accompanies this response to commentators, I have come to realize that the philosophical task of offering a theory of knowledge is orthogonal to the challenge of responding to the problem of radical scepticism. Although I still endorse most of what is contained in my first monograph-Pritchard (2005) - I think that I made the mistake there of trying to simultaneously define knowledge and resolve the sceptical problematic.

Manuscrito-Rev. Int. Fil. Campinas, v. 41, n. 1, pp. 115-165, jan.-mar. 2018. 
dispute, so far as I can tell), such that it doesn't entail that the rational grounds in question are reflectively accessible.

Given the very thin way that I understand reflective access-i.e., that the subject can cite the grounds in question without needing further empirical inquiry, as when one defends one's commitment to $p$ by saying that one can see that $p-\mathrm{I}$ don't see how this is to be done. What would it even mean to say that one has resolved the sceptical problem by showing that one has the rational grounds required for knowledge, but that one cannot cite them? And what philosophical satisfaction could this stance possibly afford us anyway? The point is clear: epistemic externalism is either formulated in a radical fashion that requires substantial revisionism, or it is formulated in a modest fashion, in which case there is no avoiding the fact that one needs to be able to offer the requisite reflectively accessible rational basis for one's knowledge. ${ }^{44}$

44 While I am grateful to all of my commentators, a special thanks is owed to Rodrigo Borges, as he was responsible for putting this symposium together.

Manuscrito - Rev. Int. Fil. Campinas, v. 41, n. 1, pp. 115-165, jan.-mar. 2018. 


\section{References}

Bonevac, D., Dever, J., \& Sosa, D. The Conditional Fallacy. The Philosophical Review, 115(3), 273-316, 2006.

Borges, R. (2015). On Synchronic Dogmatism. Synthese, 192(11), 3677-3693. Goldman, A. (1999). Internalism Exposed. Journal of Philosophy, 96 (6), 271-293. Kahneman, D. Thinking, fast and slow. Farrar, Straus and Giroux, 2011.

CAVELL, S. The claim of reason: Wittgenstein, skepticism, morality, and tragedy, cambridge, ma: harvard university press,1979.

DAVIDSON, D. 'A coherence theory of truth and knowledge', reprinted as chapter 16 in truth and interpretation: perspectives on the philosophy of Donald Davidson, (ed.) E. Lepore, Blackwell, Oxford, 1983 [1986]..

Derose, K. 'Solving the Skeptical Problem', Philosophical review 104, 1-52, 1995.

HAwthorne, J. (2005), "The Case for Closure", in Contemporary debates in Epistemology, M. Steup and E. Sosa (eds.), 26-42.

McDowell, J. 'Knowledge and the Internal', Philosophy and Phenomenological Research 55, 877-93, 1995.

MoOre, G.E. (1925), "A defense of Common Sense", in Contemporary British Philosophers, 1925, reprinted in G. E. Moore, Philosophical Papers, London: Collier Books, 1962. (1939), "Proof of an external world", Proceedings of the British academy, reprinted in Philosophical Papers.

(1925) “A Defense of Common Sense," Contemporary British Philosophy (2nd series), (ed.) J.H. Muirhead, 191-224, London: Allen \& Unwin.

"Proof of an External World," Proceedings of the British Academy 25 (5):273-300, 1939.

"Certainty" in Philosophical Papers, (New York: The MacMillan Company), 226-251, 1993.

Manuscrito - Rev. Int. Fil. Campinas, v. 41, n. 1, pp. 115-165, jan.-mar. 2018. 
Moyal-Sharrock, D. (2004), Understanding Wittgenstein's On Certainty, London: Palgrave Macmillan.

PRITCHARD, D. H. (forthcoming). 'Quasi-fideism and Religious Conviction', European Journal for Philosophy of Religion. 'Faith and Reason', Philosophy 81, 101-18, 2017. 'Epistemic Risk', Journal of Philosophy 113, 550-71, 2016.

'Wittgenstein on Faith and Reason: The Influence of Newman', God, Truth and other Enigmas, (ed.) M. Szatkowski, 141-64, Berlin, Walter de Gruyter, 2015.

'Davidson on Radical Skepticism', Blackwell Companion to Donald Davidson, (eds.) E. Lepore \& k. Ludwig, 521-33, Oxford: Blackwell, 2013.

'Anti-luck Virtue Epistemology', Journal of Philosophy 109, 247-79, 2012a.

Epistemological Disjunctivism, Oxford: Oxford University Press, 2012b.

'Wittgensteinian Quasi-fideism', Oxford Studies in the Philosophy of Religion 4, 145-59, 2011.

'Epistemic Relativism, Epistemic Incommensurability and Wittgensteinian Epistemology', Blackwell Companion to Relativism, (ed.) S. Hales, 266-85, Oxford: Blackwell, 2010.

Defusing Epistemic Relativism', Synthese 166, 397-4, 2009.

(2014, October). The Modal Account of Luck. Metaphilosophy, 45(45), 594-619.

Epistemic Angst: Radical Skepticism and the Groundless- ness of Our Believing. Princeton University Press, 2016.

(2014) "Entitlement and the Groundlessness of Our Believing", in Contemporary Perspectives on Scepticism and Perceptual Justification, D.

Dodd « E.Zardini (eds.), Oxford University Press 
(2010): 'Epistemic Relativism, Epistemic Incommensurability and Wittgensteinian Epistemology', in S.Hales (ed): Blackwell Companion to Relativism, Blackwell . (2000), "Is "God Exists" a "Hinge" Proposition of Religious Belief?", International Journal for Philosophy of Religion 47, 129-40 Epistemic Luck, Oxford: Oxford University Press, 2005a. 'The Structure of Sceptical Arguments', Philosophical Quarterly 55, 37-52, 2005b. 'Anti-Luck Epistemology', Synthese 158, 277-97, 2007. Epistemological Disjunctivism, Oxford: Oxford University Press, 2012b. 'Anti-Luck Epistemology and the Gettier Problem', Philosophical Studies 172, 93-111, 2015a.

Epistemic Angst: Radical Skepticism and the Groundlessness of Our Believing, Princeton, NJ, Princeton University Press, 2015b.

(Forthcoming). 'Anti-Risk Epistemology and Negative Epistemic Dependence', Synthese. , Millar, A., \& HadDOCK, A. The Nature and Value of Knowledge: Three Investigations, Oxford: Oxford University Press, 2010.

Putnam, H. (1981), Reason, Truth and History. Cambridge: Cambridge University Press.

SAlvatore, N.C., (2017), "'Hinge Epistemology: an Anti-Skeptical Skepticism?" ", Skepsis , 15, p. 62-82 (2016), 'Wittgenstein: Epistemology', Internet Encyclopedia of Philosophy, URL http://www.iep.utm.edu/witt-epi/ , 2016

SHOPE, R. The Conditional Fallacy in Contemporary Philosophy. The Journal of Philosophy, 75(8), 397-413 1978.

TANESINI, A. Wittgenstein: A Feminist Interpretation, London: Polity, 2004.

Veber, M. "The Argument from Abomination," Erkenntnis, 78(5): 1185-1196, 2013.

Manuscrito - Rev. Int. Fil. Campinas, v. 41, n. 1, pp. 115-165, jan.-mar. 2018. 
Williamson, T. (2000), Knowledge and Its Limits. Oxford: Oxford University Press.

Wittgenstein, L. On Certainty, (eds.) G. E. M. Anscombe \& G. H. von Wright, (tr.) D. Paul \& G. E. M. Anscombe, Oxford: Blackwell, 1969.

On Certainty, Anscombe \& von Wright (eds.), Anscombe \& von Wright, (trans.), (London: Blackwell), 1969.

On certainty, (eds.) G. E. M. Anscombe \& g. H. Von wright, (tr.) D. Paul \& g. E. M. Anscombe, oxford: blackwell, 1969.

Williamson, T. (2000). Knowledge and Its Limits. Oxford University Press. Wittgenstein, L. (1969). On Certainty (G. Anscombe \& G. von Wright, Eds.).

Oxford University Press. 
Manuscrito - Rev. Int. Fil. Campinas, v. 41, n. 1, pp. 115-165, jan.-mar. 2018. 